\title{
Triterpenoid Saponins from the Seeds of Aesculus chinensis and Their Cytotoxicities
}

\author{
Jin-Tang Cheng ${ }^{1} \cdot$ Shi-Tao Chen ${ }^{1} \cdot$ Cong Guo $^{1} \cdot$ Meng-Jiao Jiao ${ }^{1} \cdot$ Wen-Jin Cui ${ }^{1} \cdot$ Shu-Hui Wang ${ }^{1}$. \\ Zhe Deng ${ }^{1} \cdot$ Chang Chen ${ }^{1} \cdot$ Sha Chen ${ }^{1} \cdot$ Jun Zhang $^{1} \cdot$ An Liu $^{1}$
}

Received: 31 October 2017 / Accepted: 4 December 2017 / Published online: 29 December 2017

(C) The Author(s) 2017. This article is an open access publication

\section{Abstract}

Six new triterpenoid saponins, aesculusosides A-F (1-6), together with 19 known ones, were isolated from the seeds of Aesculus chinensis. The new structures were elucidated through extensive spectroscopic analyses and by comparison with previously reported data. Some of the isolates were evaluated for their cytotoxic activities against MCF-7 cell line by an MTT assay, and compounds 15, 16, 19, and 23-25 exhibited inhibitory activities against MCF-7 with $\mathrm{IC}_{50}$ values ranging from 7.1 to $31.3 \mu \mathrm{M}$.

\section{Graphical Abstract}

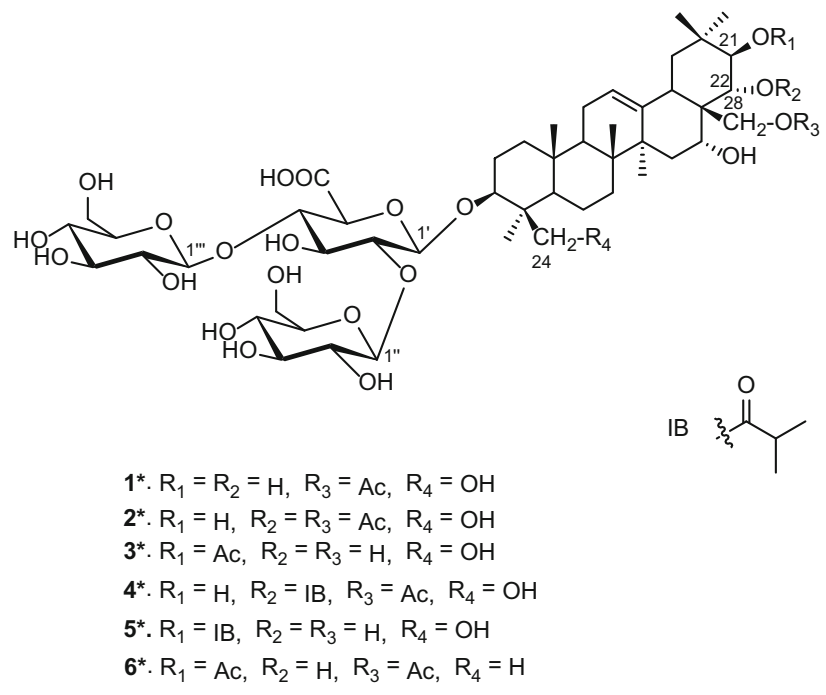

Keywords Aesculus chinensis · Triterpenoid saponins · Chemical structures · Anti-tumor activity

Jin-Tang Cheng and Shi-Tao Chen have contributed equally to this work.

Electronic supplementary material The online version of this article (https://doi.org/10.1007/s13659-017-0148-4) contains supplementary material, which is available to authorized users.

An Liu

1a62@163.com

1 Institute of Chinese Materia Medica, China Academy of Chinese Medical Sciences, Beijing 100700, China

\section{Introduction}

Hippocastanaceae is known to be a rich source of escins, a group of structurally diverse natural products characterized by a pentacyclic triterpenoid framework combined with a oligoglycoside chain [1]. Modern pharmacological studies show that some of these triterpenoid saponins possess diverse activities, including anti-inflammatory [2, 3], 
antitumor [4-7], antiviral [8], antioxidative [9, 10] and antigenotoxic properties [10].

Aesculus chinensis Bge. (Hippocastanaceae), abundant in the northwestern China, is a medicinal plant and its dried ripe seeds have been used as a stomachic and analgesic in the treatment of ditension and pain in the chest and abdomen [8]. Previous investigations on the chemical constituents of the seeds led to the isolation of an array of triterpenoid saponins $[2,8,11-13]$. In order to search for bioactive constituents from natural sources, we conducted the phytochemical investigation on the seeds of A. chinensis and identified six new (1-6) and 19 known triterpenoid saponins (7-25) (Fig. 1). Reported herein are the isolation and structure elucidation of compounds $\mathbf{1}-\mathbf{6}$, as well as the cytotoxicities of some isolates.

\section{Results and Discussion}

Compound 1 was isolated as an amorphous powder, with the molecular formula of $\mathrm{C}_{50} \mathrm{H}_{80} \mathrm{O}_{23}$ as determined by its ${ }^{13} \mathrm{C}-\mathrm{NMR}$ data and negative-ion HR-ESI-MS $(\mathrm{m} / \mathrm{z}$
1047.5035 $\left([\mathrm{M}-\mathrm{H}]^{-}\right)$, calc. 1047.5018). The IR absorption bands at 3424 and $1721 \mathrm{~nm}^{-1}$ implied the presence of the hydroxyls and carboxyl groups, respectively. In the ${ }^{1} \mathrm{H}-$ NMR spectrum (Table 1), it displayed the occurrence of one olefinic proton $\left(\delta_{\mathrm{H}} 5.28\right)$ and six methyls $\left(\delta_{\mathrm{H}} 1.43\right.$, $1.21,0.96,0.93,0.92$, and 0.88 ), which was in conformity with the appearance of one olefinic C-atom $\left(\delta_{\mathrm{C}} 129.9\right)$ and six methyls $\left(\delta_{\mathrm{C}} 30.3,27.6,23.0,19.2,17.5\right.$, and 16.4) in its ${ }^{13} \mathrm{C}-\mathrm{NMR}$ data, characteristic of a triterpenoid skeleton [15]. In addition, the presence of three anomeric carbon signals at $\delta_{\mathrm{C}} 104.9,104.8$ and 104.2, as well as other oxygenated carbon signals in the region of $\delta_{\mathrm{C}} 83.0-61.9$ in the ${ }^{13} \mathrm{C}-\mathrm{NMR}$ spectrum, indicated that there existed a trisaccharide moiety. The above evidence suggested that the structure of $\mathbf{1}$ showed a close resemblance to that of aesculuside-B [15], except for the presence of an additional acetyl group. Careful analysis of its HSQC and ${ }^{1} \mathrm{H}-{ }^{1} \mathrm{H}$ COSY spectra revealed the presence of the following fragments, a (C-1/C-2/C-3), b (C-15/C-16), c (C-21/C-22), d $\left(\mathrm{C}-1^{\prime} / \mathrm{C}-2^{\prime} / \mathrm{C}-3^{\prime} / \mathrm{C}-4^{\prime}\right)$, e $\left(\mathrm{C}-1^{\prime \prime} / \mathrm{C}-2^{\prime \prime} / \mathrm{C}-3^{\prime \prime} / \mathrm{C}-4^{\prime \prime} / \mathrm{C}-5^{\prime \prime} / \mathrm{C}-\right.$ $\left.6^{\prime \prime}\right)$, and $\mathrm{f}\left(\mathrm{C}-1^{\prime \prime \prime} / \mathrm{C}-2^{\prime \prime \prime} / \mathrm{C}-3^{\prime \prime \prime} / \mathrm{C}-4^{\prime \prime \prime} / \mathrm{C}-5^{\prime \prime \prime} / \mathrm{C}-6^{\prime \prime \prime}\right)$ as shown in Fig. 2. As observed in the HMBC spectrum, a

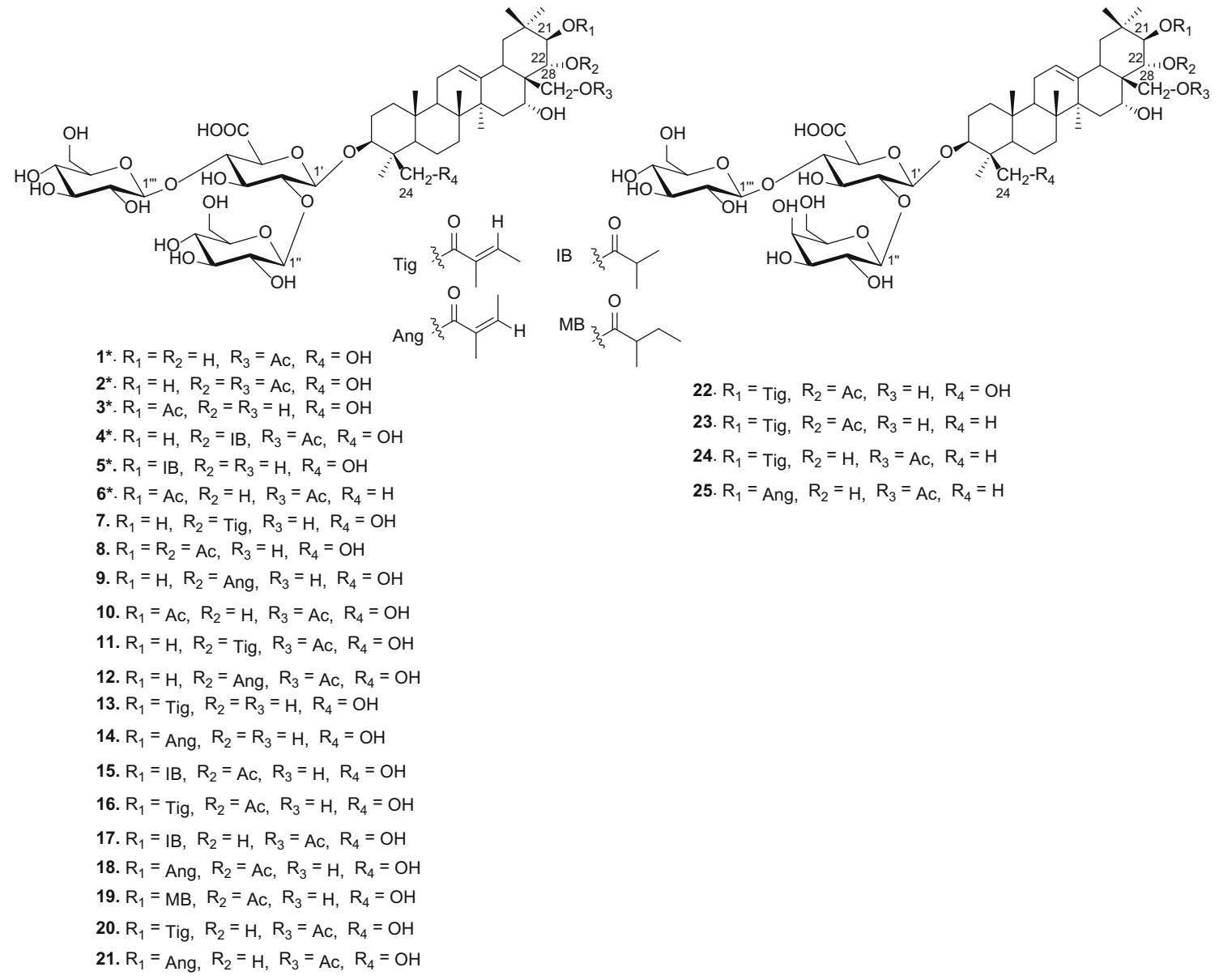

Fig. 1 Structures of compounds 1-25 
Table $1{ }^{1} \mathrm{H}-\mathrm{NMR}$ data of compounds $1-6$ recorded in methanol- $d_{4}(\delta$ in ppm, $J$ in $\mathrm{Hz}, 600 \mathrm{MHz})$

\begin{tabular}{|c|c|c|c|c|c|c|}
\hline Position & 1 & 2 & 3 & 4 & 5 & 6 \\
\hline $1 \mathrm{a}$ & $1.61, \mathrm{~m}$ & $1.63, \mathrm{~m}$ & $1.62, \mathrm{~m}$ & $1.62, \mathrm{~m}$ & $1.63, \mathrm{~m}$ & $1.61, \mathrm{~m}$ \\
\hline $1 b$ & $0.98, \mathrm{~m}$ & $1.00, \mathrm{~m}$ & $0.99, \mathrm{~m}$ & $0.99, \mathrm{~m}$ & $1.00, \mathrm{~m}$ & $0.99, \mathrm{~m}$ \\
\hline $2 \mathrm{a}$ & $2.09, \mathrm{~m}$ & $2.05, \mathrm{~m}$ & $2.09, \mathrm{~m}$ & $2.09, \mathrm{~m}$ & $2.10, \mathrm{~m}$ & $1.94, \mathrm{~m}$ \\
\hline $2 b$ & $1.81, \mathrm{~d}(12.7)$ & $1.82, \mathrm{~d}(12.3)$ & $1.82, \mathrm{~d}(12.3)$ & $1.82, \mathrm{~m}$ & $1.81, \mathrm{~d}(13.1)$ & $1.71, \mathrm{~d}(12.7)$ \\
\hline 3 & $3.37, \mathrm{~m}$ & $3.38, \mathrm{~m}$ & $3.38, \mathrm{~m}$ & $3.37, \mathrm{~m}$ & $3.38, \mathrm{~m}$ & $3.21, \mathrm{~m}$ \\
\hline 5 & 0.95 , overlap & 0.96 , overlap & 0.95 , overlap & 0.95 , overlap & 0.95 , overlap & $0.79, \mathrm{~d}(11.5)$ \\
\hline $6 a$ & $1.63, \mathrm{~m}$ & $1.63, \mathrm{~m}$ & $1.63, \mathrm{~m}$ & $1.62, \mathrm{~m}$ & $1.63, \mathrm{~m}$ & $1.61, \mathrm{~m}$ \\
\hline $6 b$ & $1.36, \mathrm{~m}$ & $1.36, \mathrm{~m}$ & $1.37, \mathrm{~m}$ & $1.37, \mathrm{~m}$ & $1.36, \mathrm{~m}$ & $1.43, \mathrm{~m}$ \\
\hline $7 \mathrm{a}$ & $1.60, \mathrm{~m}$ & $1.60, \mathrm{~m}$ & $1.61, \mathrm{~m}$ & $1.61, \mathrm{~m}$ & $1.61, \mathrm{~m}$ & $1.63, \mathrm{~m}$ \\
\hline $7 b$ & 1.36 , overlap & 1.36 , overlap & 1.36, overlap & $1.36, \mathrm{~m}$ & 1.36, overlap & $1.37, \mathrm{~d}(12.9)$ \\
\hline 9 & $1.63, \mathrm{~m}$ & $1.66, \mathrm{~m}$ & $1.65, \mathrm{~m}$ & $1.65, \mathrm{~m}$ & $1.65, \mathrm{~m}$ & $1.65, \mathrm{~m}$ \\
\hline 11 & $1.87, \mathrm{~m}, 2 \mathrm{H}$ & $1.89, \mathrm{~m}, 2 \mathrm{H}$ & $1.86, \mathrm{~m}, 2 \mathrm{H}$ & $1.86, \mathrm{~m}, 2 \mathrm{H}$ & $1.86, \mathrm{~m}, 2 \mathrm{H}$ & $1.90, \mathrm{~m}, 2 \mathrm{H}$ \\
\hline 12 & 5.28, brs & 5.33 , brs & 5.33 , brs & $5.34, \mathrm{t}(3.4)$ & 5.33 , brs & 5.31, brs \\
\hline $15 \mathrm{a}$ & $1.76, \mathrm{~m}$ & $1.71, \mathrm{dd}(12.0,3.2)$ & 1.78, dd $(14.7,3.0)$ & $1.69, \mathrm{~m}$ & 1.77, dd $(14.9,3.2)$ & 1.78, dd $(14.7,3.2)$ \\
\hline $15 b$ & $1.40, \mathrm{~m}$ & $1.39, \mathrm{~m}$ & $1.38, \mathrm{~m}$ & $1.39, \mathrm{~m}$ & $1.37, \mathrm{~m}$ & $1.45, \mathrm{~m}$ \\
\hline 16 & 4.11, brs & 4.11, brs & 4.12, brs & 4.10, brs & 4.11, brs & 4.11, brs \\
\hline 18 & $2.45, \mathrm{~m}$ & 2.46, dd $(13.9,3.3)$ & 2.42, dd $(14.1,3.3)$ & $2.54, \mathrm{~m}$ & 2.43, dd $(14.1,3.3)$ & 2.49, dd $(14.0,3.4)$ \\
\hline $19 \mathrm{a}$ & $2.47, \mathrm{~m}$ & $2.57, \mathrm{t}(13.5)$ & $2.56, \mathrm{~m}$ & 2.54 , overlap & $2.56, \mathrm{~m}$ & $2.61, \mathrm{t}(13.6)$ \\
\hline $19 b$ & $1.07, \mathrm{dd}(12.0,2.6)$ & $1.12, \mathrm{~m}$ & $1.12, \mathrm{~d}(4.5)$ & 1.12, dd $(12.4,3.6)$ & $1.11, \mathrm{dd}(13.0,4.0)$ & 1.15, dd $(12.9,4.0)$ \\
\hline 21 & $3.94, \mathrm{~d}(9.6)$ & $4.18, \mathrm{~d}(9.8)$ & $5.50, \mathrm{~d}(10.0)$ & $4.21, \mathrm{~d}(9.9)$ & $5.49, \mathrm{~d}(10.0)$ & $5.51, \mathrm{~d}(9.9)$ \\
\hline 22 & $3.71, \mathrm{~d}(9.6)$ & $5.21, \mathrm{~d}(9.8)$ & $3.96, \mathrm{~d}(10.0)$ & $5.23, \mathrm{~d}(9.9)$ & $3.96, \mathrm{~d}(10.0)$ & $3.88, \mathrm{~d}(9.9)$ \\
\hline 23 & $1.20, \mathrm{~s}$ & $1.21, \mathrm{~s}$ & $1.21, \mathrm{~s}$ & $1.20, \mathrm{~s}$ & $1.20, \mathrm{~s}$ & $1.10, \mathrm{~s}$ \\
\hline $24 \mathrm{a}$ & 4.10, brs & 4.10, brs & 4.10, brs & 4.10, brs & 4.10, brs & $0.87(3 \mathrm{H}, \mathrm{s})$ \\
\hline $24 b$ & $3.21, \mathrm{~m}$ & $3.21, \mathrm{~m}$ & $3.21, \mathrm{~m}$ & $3.21, \mathrm{~m}$ & $3.20, \mathrm{~m}$ & \\
\hline 25 & $0.87, \mathrm{~s}$ & $0.87, \mathrm{~s}$ & $0.88, \mathrm{~s}$ & $0.87, \mathrm{~s}$ & $0.88, \mathrm{~s}$ & $0.97, \mathrm{~s}$ \\
\hline 26 & $0.91, \mathrm{~s}$ & $0.88, \mathrm{~s}$ & $0.92, \mathrm{~s}$ & $0.88, \mathrm{~s}$ & $0.92, \mathrm{~s}$ & $0.93, \mathrm{~s}$ \\
\hline 27 & $1.42, \mathrm{~s}$ & $1.45, \mathrm{~s}$ & $1.44, \mathrm{~s}$ & $1.46, \mathrm{~s}$ & $1.43, \mathrm{~s}$ & $1.44, \mathrm{~s}$ \\
\hline $28 \mathrm{a}$ & $3.84, \mathrm{t}(11.2)$ & 4.11, brs & $3.34, \mathrm{~m}$ & $3.64, \mathrm{~m}$ & $3.32, \mathrm{~m}$ & $3.87, \mathrm{~m}$ \\
\hline $28 b$ & $3.76, \mathrm{~m}$ & $3.64, \mathrm{~m}$ & $3.22, \mathrm{~m}$ & 3.56, brs & $3.22, \mathrm{~m}$ & $3.74, \mathrm{~m}$ \\
\hline 29 & $0.96, \mathrm{~s}$ & $0.97, \mathrm{~s}$ & $0.83, \mathrm{~s}$ & $0.96, \mathrm{~s}$ & $0.82, \mathrm{~s}$ & $0.85, \mathrm{~s}$ \\
\hline 30 & $0.92, \mathrm{~s}$ & $0.98, \mathrm{~s}$ & $0.98, \mathrm{~s}$ & $0.99, \mathrm{~s}$ & $0.99, \mathrm{~s}$ & $1.00, \mathrm{~s}$ \\
\hline $1^{\prime}$ & $4.50, \mathrm{~d}(7.6)$ & $4.52, \mathrm{~d}(7.2)$ & $4.50, \mathrm{~d}(7.5)$ & $4.49, \mathrm{~d}(7.8)$ & $4.49, \mathrm{~d}(7.7)$ & $4.50, \mathrm{~d}(6.6)$ \\
\hline $2^{\prime}$ & $3.62, \mathrm{~m}$ & $3.62, \mathrm{~m}$ & $3.62, \mathrm{~m}$ & $3.62, \mathrm{~m}$ & $3.61, \mathrm{~m}$ & $3.70, \mathrm{~m}$ \\
\hline $3^{\prime}$ & $3.75, \mathrm{~m}$ & $3.76, \mathrm{~m}$ & $3.75, \mathrm{~m}$ & $3.76, \mathrm{~m}$ & $3.75, \mathrm{~m}$ & $3.74, \mathrm{~m}$ \\
\hline $4^{\prime}$ & $3.63, \mathrm{~m}$ & $3.71, \mathrm{~m}$ & $3.63, \mathrm{~m}$ & $3.64, \mathrm{~m}$ & $3.62, \mathrm{~m}$ & $3.71, \mathrm{~m}$ \\
\hline $5^{\prime}$ & 3.62, overlap & 3.62, overlap & 3.62 , overlap & 3.62 , overlap & 3.62, overlap & $3.23, \mathrm{~m}$ \\
\hline $1^{\prime \prime}$ & $4.83, \mathrm{~d}(7.8)$ & $4.83, \mathrm{~d}(7.7)$ & $4.83, \mathrm{~d}(7.7)$ & $4.83, \mathrm{~d}(7.9)$ & $4.83, \mathrm{~d}(7.7)$ & $4.72, \mathrm{~d}(7.6)$ \\
\hline $2^{\prime \prime}$ & $3.19, \mathrm{~m}$ & $3.19, \mathrm{~m}$ & $3.19, \mathrm{~m}$ & $3.19, \mathrm{~m}$ & $3.19, \mathrm{~m}$ & 3.23 , overlap \\
\hline $3^{\prime \prime}$ & $3.35, \mathrm{~m}$ & $3.35, \mathrm{~m}$ & $3.35, \mathrm{~m}$ & $3.35, \mathrm{~m}$ & $3.35, \mathrm{~m}$ & $3.35, \mathrm{~m}$ \\
\hline $4^{\prime \prime}$ & $3.46, \mathrm{t}(9.3)$ & $3.46, \mathrm{t}(9.3)$ & $3.46, \mathrm{t}(9.4)$ & $3.46, \mathrm{t}(9.4)$ & $3.44, \mathrm{t}(9.4)$ & $3.32, \mathrm{~m}$ \\
\hline $5^{\prime \prime}$ & 3.34, overlap & 3.34 , overlap & 3.34, overlap & 3.34, overlap & 3.35 , overlap & 3.35 , overlap \\
\hline $6 \mathrm{a}^{\prime \prime}$ & $3.77, \mathrm{~m}$ & $3.77, \mathrm{~m}$ & $3.77, \mathrm{~m}$ & $3.77, \mathrm{~m}$ & $3.77, \mathrm{~m}$ & $3.87, \mathrm{~m}$ \\
\hline $6 b^{\prime \prime}$ & $3.73, \mathrm{~m}$ & $3.73, \mathrm{~m}$ & $3.73, \mathrm{~m}$ & $3.73, \mathrm{~m}$ & $3.73, \mathrm{~m}$ & $3.68, \mathrm{~m}$ \\
\hline $1^{\prime \prime \prime}$ & 4.42 , brs & 4.41, brs & 4.42 , brs & $4.42, \mathrm{~d}(6.5)$ & $4.42, \mathrm{~d}(6.2)$ & 4.44 , brs \\
\hline $2^{\prime \prime \prime}$ & $3.23, \mathrm{~m}$ & $3.23, \mathrm{~m}$ & $3.23, \mathrm{~m}$ & $3.23, \mathrm{~m}$ & $3.23, \mathrm{~m}$ & $3.22, \mathrm{~m}$ \\
\hline $3^{\prime \prime \prime}$ & $3.38, \mathrm{~m}$ & $3.38, \mathrm{~m}$ & $3.38, \mathrm{~m}$ & $3.38, \mathrm{~m}$ & $3.38, \mathrm{~m}$ & $3.36, \mathrm{~m}$ \\
\hline $4^{\prime \prime \prime}$ & $3.30, \mathrm{~m}$ & $3.30, \mathrm{~m}$ & $3.30, \mathrm{~m}$ & $3.30, \mathrm{~m}$ & $3.30, \mathrm{~m}$ & $3.22, \mathrm{~m}$ \\
\hline $5^{\prime \prime \prime}$ & $3.31, \mathrm{~m}$ & $3.34, \mathrm{~m}$ & $3.36, \mathrm{~m}$ & $3.35, \mathrm{~m}$ & $3.35, \mathrm{~m}$ & $3.23, \mathrm{~m}$ \\
\hline
\end{tabular}


Table 1 (continued)

\begin{tabular}{|c|c|c|c|c|c|c|}
\hline Position & 1 & 2 & 3 & 4 & 5 & 6 \\
\hline $6 a^{\prime \prime \prime}$ & $3.87, \mathrm{~d}(11.2)$ & $3.87, \mathrm{~d}(11.0)$ & $3.87, \mathrm{~d}(11.6)$ & $3.86, \mathrm{~d}(11.6)$ & $3.85, \mathrm{~d}(11.9)$ & $3.82, \mathrm{~d}(11.3)$ \\
\hline $6 b^{\prime \prime \prime}$ & $3.66, \mathrm{~m}$ & $3.66, \mathrm{~m}$ & $3.66, \mathrm{~m}$ & $3.66, \mathrm{~m}$ & $3.64, \mathrm{~m}$ & $3.62, \mathrm{~m}$ \\
\hline \multicolumn{7}{|c|}{ 21- $O$-moiety } \\
\hline $2^{\prime \prime \prime \prime}$ & & & $2.09, \mathrm{~s}$ & & $2.61, \mathrm{~m}$ & $2.09, \mathrm{~s}$ \\
\hline $3^{\prime \prime \prime \prime}$ & & & & & $1.18, \mathrm{~s}$ & \\
\hline $4^{\prime \prime \prime \prime}$ & & & & & $1.20, \mathrm{~s}$ & \\
\hline \multicolumn{7}{|c|}{ 22-O-moiety } \\
\hline $2^{\prime \prime \prime \prime}$ & & $2.08, \mathrm{~s}$ & & $2.62, \mathrm{~m}$ & & \\
\hline $3^{\prime \prime \prime \prime}$ & & & & $1.18, \mathrm{~d}(7.2)$ & & \\
\hline $4^{\prime \prime \prime \prime}$ & & & & $1.19, \mathrm{~d}(7.2)$ & & \\
\hline \multicolumn{7}{|c|}{ 28-O-moiety } \\
\hline $2^{\prime \prime \prime \prime}$ & $2.05, \mathrm{~s}$ & $2.02, \mathrm{~s}$ & & $2.04, \mathrm{~s}$ & & $2.05, \mathrm{~s}$ \\
\hline
\end{tabular}

correlation between the signals of $\mathrm{CH}_{2}\left(\delta_{\mathrm{H}} 3.84\right.$ and 3.76, $\left.\mathrm{H}_{2}-28\right)$ and the acetyl carbons $\left(\delta_{\mathrm{C}} 173.0\right.$ and 21.0) revealed that the acyl group was attached to $\mathrm{C}-28$. Furthermore, the trisaccharidic structure was characterized by HMBC crosspeaks of H-1' $\left(\delta_{\mathrm{H}} 4.50\right) / \mathrm{C}-3\left(\delta_{\mathrm{C}} 92.5\right), \mathrm{H}-1^{\prime \prime}\left(\delta_{\mathrm{H}} 4.83\right) / \mathrm{C}-2^{\prime}$ $\left(\delta_{\mathrm{C}} 80.2\right)$ and $\mathrm{H}-1^{\prime \prime \prime}\left(\delta_{\mathrm{H}} 4.42\right) / \mathrm{C}-4^{\prime}\left(\delta_{\mathrm{C}} 82.9\right)$. In the ROESY spectrum of $\mathbf{1}$, there were no solid correlations which can be used to establish the relative configurations of C-3, C-16, C-21, and C-22. Thus, alkaline hydrolysis of 1 with $1 \% \mathrm{NaOMe}$, which liberated aesculuside-B, was conducted to assign the stereochemistry of chiral centers in 1 [15]. Furthermore, the coupling constant of H-21 and $\mathrm{H}-22(J=9.6 \mathrm{~Hz})$ also supported the proposed stereochemistry of C-21 and C-22 [8]. Acid hydrolysis of $\mathbf{1}$ yielded glucose and glucuronic acid. The three monosaccharides were determined to be one $\beta$-D-glucuronopyranosyl acid and two $\beta$-D-glucopyranoses inferring from the coupling constants of the anomeric protons $\left(\delta_{\mathrm{H}} 4.50, \mathrm{~d}\right.$, $\left.J=7.6 \mathrm{~Hz}, \mathrm{H}-1^{\prime} ; \delta_{\mathrm{H}} 4.83, \mathrm{~d}, J=7.8 \mathrm{~Hz}, \mathrm{H}-1^{\prime \prime}\right)$ and the typical carbon chemical shifts $\left(\delta_{\mathrm{C}} 104.9, \mathrm{C}-1^{\prime} ; \delta_{\mathrm{C}} 104.2\right.$, $\left.\mathrm{C}-1^{\prime \prime} ; \delta_{\mathrm{C}} 104.7, \mathrm{C}-1^{\prime \prime \prime}\right)$. Based on the above evidence, compound 1 was characterized as $28-O$-acetylprotoaescigenin $\quad 3-O$ - $[\beta$-D-glucopyranosyl $(1 \rightarrow 2)][\beta$-D-glucopyra$\operatorname{nosyl}(1 \rightarrow 4)]-\beta$-D-glucopyranosiduronic acid.

Compound 2, obtained as an amorphous powder, was assigned to have a molecular formula of $\mathrm{C}_{52} \mathrm{H}_{82} \mathrm{O}_{24}$ by negative-ion HR-ESI-MS $\left(\mathrm{m} / z 1089.5107\left([\mathrm{M}-\mathrm{H}]^{-}\right)\right.$, calc. 1089.5123). The ${ }^{1} \mathrm{H}$ and ${ }^{13} \mathrm{C}$ NMR data of 2 (Tables 1,2 ) exhibited an identical trisaccharide moiety and aglycone as 1. The only difference between them was an additional acetyl group in $\mathbf{2}$, with an extra characteristic proton signal at $\delta_{\mathrm{H}} 2.08$ in its ${ }^{1} \mathrm{H}-\mathrm{NMR}$ spectrum and two additional carbon signals at $\delta_{\mathrm{C}} 173.5,21.4$ in its ${ }^{13} \mathrm{C}$-NMR spectrum. Detailed analysis of its 1D and 2D NMR spectra suggested that the additional acetyl group was attached to C-22, which could be deduced by the key HMBC cross-peak of $\mathrm{H}-22\left(\delta_{\mathrm{H}} 5.21\right) / \mathrm{C}-1^{\prime \prime \prime \prime}\left(\delta_{\mathrm{C}}\right.$ 173.5). The downfield shift of $\mathrm{H}-22$ further supported the above conclusion. Therefore, 2 was established as 22,28-O-diacetyl-protoaescigenin 3-O$[\beta$-D-glucopyranosyl- $(1 \rightarrow 2)][\beta$-D-glucopyranosyl- $(1 \rightarrow 4)]$ $\beta$-D-glucuronopyranosyl acid.

Compound 3 was determined to have the same molecular formula of $\mathrm{C}_{50} \mathrm{H}_{80} \mathrm{O}_{23}$ as $\mathbf{1}$ by its negative-ion HRESI-MS $\left(m / z, 1047.5005\left([\mathrm{M}-\mathrm{H}]^{-}\right)\right.$, calc. 1047.5018). The characteristic NMR data suggested that $\mathbf{3}$ had the similar structure as 1. The significant differences in ${ }^{1} \mathrm{H}$ and ${ }^{13} \mathrm{C}$ NMR spectra from those of $\mathbf{1}$ and $\mathbf{3}$ were chemical shifts of $\mathrm{C}-21\left(\delta_{\mathrm{C}} 82.8\right)$ and $\mathrm{C}-22\left(\delta_{\mathrm{C}} 73.9\right)$ with corresponding protons at $\delta_{\mathrm{H}} 5.50$ and 3.97. The downfield shifts of C-21 implied that the acetyl group at the C-22 in $\mathbf{1}$ was transferred to $\mathrm{C}-21$ in $\mathbf{3}$, which was further confirmed by the key HMBC cross-peak of $\mathrm{H}-21\left(\delta_{\mathrm{H}} 5.50\right) / \mathrm{C}-1^{\prime \prime \prime \prime}\left(\delta_{\mathrm{C}} 174.0\right)$. In addition, the alkaline hydrolysis of $\mathbf{3}$ yielded aesculuside- $\mathrm{B}$ [15]. Hence, the structure of $\mathbf{3}$ was determined as 21- $O$ acetylprotoaescigenin $3-O-[\beta$-D-glucopyranosyl $(1 \rightarrow 2)][\beta$ D-glucopyranosyl $(1 \rightarrow 4)]$ - $\beta$-D-glucopyranosiduronic acid.

The HR-ESI-MS data of 4 showed a $[\mathrm{M}-\mathrm{H}]^{-}$ion at $\mathrm{m} / \mathrm{z}$ 1117.5425 (calc. 1117.5436), corresponding to a molecular formula of $\mathrm{C}_{54} \mathrm{H}_{86} \mathrm{O}_{24}$. The similar NMR data between 4 and $\mathbf{2}$ indicated that they are very close in the structure. Furthermore, the ${ }^{1} \mathrm{H}-\mathrm{NMR}$ spectrum of $\mathbf{4}$ displayed one methine proton $\left(\delta_{\mathrm{H}} 2.62\right)$ and two doublet methyl protons $\left(\delta_{\mathrm{H}} 1.18\right.$ and 1.19), with the corresponding carbon resonances at $\delta_{\mathrm{C}} 35.7,19.5$ and 19.9 in its ${ }^{13} \mathrm{C}$-NMR spectrum. An isopropyl group was easily assembled by ${ }^{1} \mathrm{H}-{ }^{1} \mathrm{H}$ COSY correlations of $\mathrm{H}-2^{\prime \prime \prime \prime}\left(\delta_{\mathrm{H}} 2.62\right)$ with $\mathrm{H}-3^{\prime \prime \prime \prime}\left(\delta_{\mathrm{H}} 1.18\right)$ and $\mathrm{H}-4^{\prime \prime \prime \prime}\left(\delta_{\mathrm{H}} 1.19\right)$. The aforementioned data, together with the key HMBC cross-peaks of H-22 $\left(\delta_{\mathrm{H}} 5.23\right) / \mathrm{C}-1^{\prime \prime \prime \prime}\left(\delta_{\mathrm{C}}\right.$ $179.3), \mathrm{H}-2^{\prime \prime \prime \prime}\left(\delta_{\mathrm{H}} 2.62\right) / \mathrm{C}-1^{\prime \prime \prime \prime}\left(\delta_{\mathrm{C}} 179.3\right), \mathrm{H}-3^{\prime \prime \prime \prime}\left(\delta_{\mathrm{H}} 1.18\right) /$ $\mathrm{C}-1^{\prime \prime \prime \prime}\left(\delta_{\mathrm{C}} 179.3\right)$ and $\mathrm{H}-4^{\prime \prime \prime \prime}\left(\delta_{\mathrm{H}} 1.19\right) / \mathrm{C}-1^{\prime \prime \prime \prime}\left(\delta_{\mathrm{C}} 179.3\right)$, 

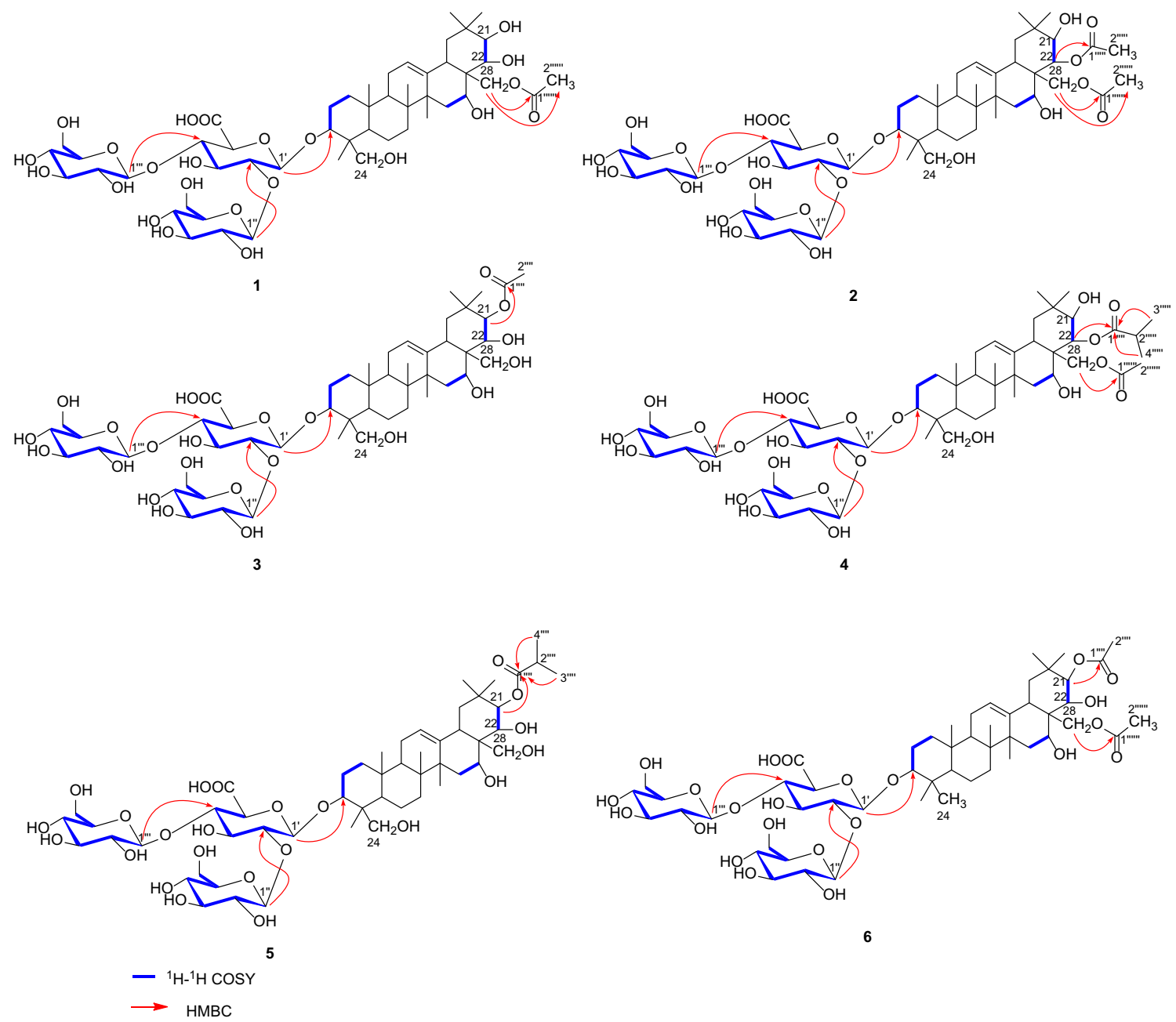

Fig. 2 Key COSY and HMBC correlations of compounds 1-6

suggested that the isopropyl group in $\mathbf{4}$ was installed at the $\mathrm{C}-1^{\prime \prime \prime \prime}$. Based on the above evidence, compound 4 was characterized as 22- $O$-isobutyryl-28- $O$-acetylprotoaescigenin $\quad 3-O$ - $[\beta$-D-glucopyranosyl $(1 \rightarrow 2)][\beta$-D-glucopyra$\operatorname{nosyl}(1 \rightarrow 4)]-\beta$-D-glucopyranosiduronic acid.

Compound $\mathbf{5}$ was isolated as an amorphous powder. Its molecular formula was determined by negative HR-ESIMS $\left[m / z \quad 1075.5406\right.$ (calc. 1075.5331)] as $\mathrm{C}_{52} \mathrm{H}_{84} \mathrm{O}_{23}$, requiring 11 degrees of unsaturation. Careful comparison of the ${ }^{1} \mathrm{H}$ and ${ }^{13} \mathrm{C}$-NMR spectra of 5 with those of 4 indicated a high degree of similarity. The differences between $\mathbf{5}$ and $\mathbf{4}$ were the absence of an acetic group at the C-28 and that the isopropyl group was transferred to C-21 other than $\mathrm{C}-22$ in compound $\mathbf{4}$, as confirmed by the combinational analysis of 2D NMR data (Fig. 2). Thus, compound 5 was elucidated as 21-O-isobutyrylprotoaescigenin $3-O$ - $[\beta$-D-glucopyranosyl $(1 \rightarrow 2)][\beta$-D-glucopyra$\operatorname{nosyl}(1 \rightarrow 4)]-\beta$-D-glucopyranosiduronic acid.

Compound 6 was obtained as an amorphous powder and gave a molecular formula of $\mathrm{C}_{52} \mathrm{H}_{82} \mathrm{O}_{23}$, as determined by
HR-ESI-MS at $m / z, 1073.5162$ (calc. 1073.5174). The ${ }^{1} \mathrm{H}-$ NMR spectrum of 6 (Table 1 ) revealed nine methyls $\left[\delta_{\mathrm{H}}\right.$ $0.84(3 \mathrm{H}, \mathrm{s}), 0.86(3 \mathrm{H}, \mathrm{s}), 0.93(3 \mathrm{H}, \mathrm{s}), 0.97(3 \mathrm{H}, \mathrm{s}), 1.00$ $(3 \mathrm{H}, \mathrm{s}), 1.09(3 \mathrm{H}, \mathrm{s}), 1.44(3 \mathrm{H}, \mathrm{s}), 2.06(3 \mathrm{H}, \mathrm{s}), 2.09(3 \mathrm{H}$, s)] and one olefinic proton $\left(\delta_{\mathrm{H}}\right.$ 5.31). The above data, together with its ${ }^{13} \mathrm{C}$-NMR data (Table 2), indicated that aglycone moiety in 6 was barringtogenol C [16]. Furthermore, the characteristic carbon resonances displayed in the region of $\delta_{\mathrm{C}} 83.0-62.6$ in its ${ }^{13} \mathrm{C}-\mathrm{NMR}$ data (Table 2), indicated that there also existed a trisaccharide moiety. Acid hydrolysis of $\mathbf{6}$ also yielded glucose and glucuronic acid. The HMBC correlations from $\mathrm{H}-21$ to $\mathrm{C}-20 / \mathrm{C}-22 / \mathrm{C}-$ $29 / \mathrm{C}-30 / \mathrm{C}-1^{\prime \prime \prime \prime}$, and from $\mathrm{H}-28$ to $\mathrm{C}-1^{\prime \prime \prime \prime}$, allowed for the assignment of two acetyl groups as shown in Fig. 1. Hence, the structure of 6 was deduced as 21,28- $O$-diacetylbarringtogenol $\mathrm{C} 3-O$-[ $\beta$-D-glucopyranosyl $(1 \rightarrow 2)][\beta$-D-glucopyranosyl $(1 \rightarrow 4)]$ - $\beta$-D-glucopyranosiduronic acid.

The 19 known compounds were identified as 22- $O$ tigloylprotoaescigenin $3-O-[\beta$-D-glucopyranosyl $(1 \rightarrow 2)][\beta$ D-glucopyranosyl $(1 \rightarrow 4)]$ - $\beta$-D-glucopyranosiduronic acid 
Table $2{ }^{13} \mathrm{C}$-NMR data of compounds 1-6 recorded in methanol- $d_{4}(\delta$ in ppm, $150 \mathrm{MHz}$ )

\begin{tabular}{|c|c|c|c|c|c|c|}
\hline Position & 1 & 2 & 3 & 4 & 5 & 6 \\
\hline 1 & $39.8, \mathrm{CH}_{2}$ & $39.8, \mathrm{CH}_{2}$ & $39.8, \mathrm{CH}_{2}$ & $39.8, \mathrm{CH}_{2}$ & $39.8, \mathrm{CH}_{2}$ & $40.1, \mathrm{CH}_{2}$ \\
\hline 2 & 27.2, $\mathrm{CH}_{2}$ & 27.2, $\mathrm{CH}_{2}$ & 27.2, $\mathrm{CH}_{2}$ & 27.2, $\mathrm{CH}_{2}$ & 27.2, $\mathrm{CH}_{2}$ & 27.2, $\mathrm{CH}_{2}$ \\
\hline 3 & $92.5, \mathrm{CH}$ & $92.6, \mathrm{CH}$ & $92.5, \mathrm{CH}$ & $92.5, \mathrm{CH}$ & $92.5, \mathrm{CH}$ & 91.6, CH \\
\hline 4 & $44.7, \mathrm{C}$ & 44.6, C & $44.6, \mathrm{C}$ & $44.6, \mathrm{C}$ & $44.6, \mathrm{C}$ & 40.6, C \\
\hline 5 & 57.6, $\mathrm{CH}$ & $57.5, \mathrm{CH}$ & $57.5, \mathrm{CH}$ & $57.5, \mathrm{CH}$ & $57.6, \mathrm{CH}$ & $57.1, \mathrm{CH}$ \\
\hline 6 & $19.5, \mathrm{CH}_{2}$ & $19.5, \mathrm{CH}_{2}$ & $19.5, \mathrm{CH}_{2}$ & $19.5, \mathrm{CH}_{2}$ & $19.5, \mathrm{CH}_{2}$ & $19.4, \mathrm{CH}_{2}$ \\
\hline 7 & $34.3, \mathrm{CH}_{2}$ & $34.2, \mathrm{CH}_{2}$ & $34.3, \mathrm{CH}_{2}$ & $34.2, \mathrm{CH}_{2}$ & $34.3, \mathrm{CH}_{2}$ & $34.2, \mathrm{CH}_{2}$ \\
\hline 8 & $41.0, \mathrm{C}$ & $40.9, \mathrm{C}$ & $41.0, \mathrm{C}$ & $41.0, \mathrm{C}$ & $41.0, \mathrm{C}$ & $41.0, \mathrm{C}$ \\
\hline 9 & $48.1, \mathrm{CH}$ & $47.9, \mathrm{CH}$ & $48.1, \mathrm{CH}$ & $48.0, \mathrm{CH}$ & $48.1, \mathrm{CH}$ & $48.1, \mathrm{CH}$ \\
\hline 10 & $37.6, \mathrm{C}$ & $37.5, \mathrm{C}$ & $37.5, \mathrm{C}$ & $37.5, \mathrm{C}$ & $37.6, \mathrm{C}$ & $37.2, \mathrm{C}$ \\
\hline 11 & $25.0, \mathrm{CH}_{2}$ & $25.0, \mathrm{CH}_{2}$ & $24.9, \mathrm{CH}_{2}$ & $25.0, \mathrm{CH}_{2}$ & $25.0, \mathrm{CH}_{2}$ & $24.8, \mathrm{CH}_{2}$ \\
\hline 12 & $125.0, \mathrm{CH}$ & $125.4, \mathrm{CH}$ & $124.7, \mathrm{CH}$ & $125.4, \mathrm{CH}$ & $124.8, \mathrm{CH}$ & $125.4, \mathrm{CH}$ \\
\hline 13 & $143.5, \mathrm{C}$ & $143.1, \mathrm{C}$ & 143.6, C & $143.2, \mathrm{C}$ & 143.6, C & $143.2, \mathrm{C}$ \\
\hline 14 & $42.6, \mathrm{C}$ & $42.3, \mathrm{C}$ & 42.6, C & 42.6, C & $42.6, \mathrm{C}$ & $42.0, \mathrm{C}$ \\
\hline 15 & $34.9, \mathrm{CH}_{2}$ & $35.1, \mathrm{CH}_{2}$ & 34.6, $\mathrm{CH}_{2}$ & $35.1, \mathrm{CH}_{2}$ & $34.7, \mathrm{CH}_{2}$ & $34.9, \mathrm{CH}_{2}$ \\
\hline 16 & $69.1, \mathrm{CH}$ & $69.1, \mathrm{CH}$ & $68.9, \mathrm{CH}$ & $69.4, \mathrm{CH}$ & $68.9, \mathrm{CH}$ & $68.9, \mathrm{CH}$ \\
\hline 17 & $47.2, \mathrm{C}$ & $46.8, \mathrm{C}$ & $48.5, \mathrm{C}$ & $46.9, \mathrm{C}$ & 48.6, C & 47.6, C \\
\hline 18 & $41.5, \mathrm{CH}$ & $42.1, \mathrm{CH}$ & $41.1, \mathrm{CH}$ & $42.1, \mathrm{CH}$ & 41.1, CH & $41.3, \mathrm{CH}$ \\
\hline 19 & $48.5, \mathrm{CH}_{2}$ & $48.3, \mathrm{CH}_{2}$ & $48.4, \mathrm{CH}_{2}$ & 48.1, $\mathrm{CH}_{2}$ & $48.4, \mathrm{CH}_{2}$ & 48.0, $\mathrm{CH}_{2}$ \\
\hline 20 & $36.8, \mathrm{C}$ & $37.4, \mathrm{C}$ & $36.6, \mathrm{C}$ & $37.3, \mathrm{C}$ & $36.8, \mathrm{C}$ & $36.6, \mathrm{C}$ \\
\hline 21 & $79.9, \mathrm{CH}$ & $77.6, \mathrm{CH}$ & $82.8, \mathrm{CH}$ & 77.7, CH & $82.4, \mathrm{CH}$ & $82.6, \mathrm{CH}$ \\
\hline 22 & 74.6, CH & $78.2, \mathrm{CH}$ & 73.9, $\mathrm{CH}$ & 76.9, $\mathrm{CH}$ & $73.9, \mathrm{CH}$ & $72.3, \mathrm{CH}$ \\
\hline 23 & $23.0, \mathrm{CH}_{3}$ & $23.0, \mathrm{CH}_{3}$ & $22.9, \mathrm{CH}_{3}$ & $23.0, \mathrm{CH}_{3}$ & $23.0, \mathrm{CH}_{3}$ & 28.6, $\mathrm{CH}_{3}$ \\
\hline 24 & $64.4, \mathrm{CH}_{2}$ & $64.5, \mathrm{CH}_{2}$ & $64.4, \mathrm{CH}_{2}$ & $64.4, \mathrm{CH}_{2}$ & $64.4, \mathrm{CH}_{2}$ & 17.1, $\mathrm{CH}_{2}$ \\
\hline 25 & $16.4, \mathrm{CH}_{3}$ & $16.4, \mathrm{CH}_{3}$ & $16.3, \mathrm{CH}_{3}$ & $16.4, \mathrm{CH}_{3}$ & $16.3, \mathrm{CH}_{3}$ & $16.3, \mathrm{CH}_{3}$ \\
\hline 26 & 17.5, $\mathrm{CH}_{3}$ & $17.3, \mathrm{CH}_{3}$ & $17.4, \mathrm{CH}_{3}$ & $17.4, \mathrm{CH}_{3}$ & $17.4, \mathrm{CH}_{3}$ & 17.6, $\mathrm{CH}_{3}$ \\
\hline 27 & 27.6, $\mathrm{CH}_{3}$ & $27.7, \mathrm{CH}_{3}$ & 27.6, $\mathrm{CH}_{3}$ & 27.7, $\mathrm{CH}_{3}$ & $27.7, \mathrm{CH}_{3}$ & $27.7, \mathrm{CH}_{3}$ \\
\hline 28 & $67.5, \mathrm{CH}_{2}$ & $68.7, \mathrm{CH}_{2}$ & 66.6, $\mathrm{CH}_{2}$ & $67.9, \mathrm{CH}_{2}$ & $66.6, \mathrm{CH}_{2}$ & $67.0, \mathrm{CH}_{2}$ \\
\hline 29 & $30.3, \mathrm{CH}_{3}$ & $30.0, \mathrm{CH}_{3}$ & $30.0, \mathrm{CH}_{3}$ & $30.0, \mathrm{CH}_{3}$ & $29.9, \mathrm{CH}_{3}$ & 29.9, $\mathrm{CH}_{3}$ \\
\hline 30 & $19.2, \mathrm{CH}_{3}$ & $19.3, \mathrm{CH}_{3}$ & $20.1, \mathrm{CH}_{3}$ & $19.2, \mathrm{CH}_{3}$ & $20.2, \mathrm{CH}_{3}$ & $20.0, \mathrm{CH}_{3}$ \\
\hline $1^{\prime}$ & $104.9, \mathrm{CH}$ & $105.1, \mathrm{CH}$ & $104.9, \mathrm{CH}$ & $104.9, \mathrm{CH}$ & $104.9, \mathrm{CH}$ & 105.6, CH \\
\hline $2^{\prime}$ & $80.3, \mathrm{CH}$ & $80.0, \mathrm{CH}$ & $80.1, \mathrm{CH}$ & $80.1, \mathrm{CH}$ & $80.1, \mathrm{CH}$ & $80.4, \mathrm{CH}$ \\
\hline $3^{\prime}$ & 77.6, $\mathrm{CH}$ & 77.6, CH & $77.5, \mathrm{CH}$ & 77.5, CH & $77.5, \mathrm{CH}$ & 77.2, $\mathrm{CH}$ \\
\hline $4^{\prime}$ & $83.0, \mathrm{CH}$ & $82.3, \mathrm{CH}$ & $83.0, \mathrm{CH}$ & $82.9, \mathrm{CH}$ & 83.0, CH & $82.9, \mathrm{CH}$ \\
\hline $5^{\prime}$ & 77.6, CH & $77.2, \mathrm{CH}$ & $77.5, \mathrm{CH}$ & $77.5, \mathrm{CH}$ & $77.5, \mathrm{CH}$ & $76.5, \mathrm{CH}$ \\
\hline $6^{\prime}$ & ND & ND & ND & ND & ND & $172.3, \mathrm{C}$ \\
\hline $1^{\prime \prime}$ & $104.2, \mathrm{CH}$ & $104.2, \mathrm{CH}$ & 104.1, CH & $104.1, \mathrm{CH}$ & $104.2, \mathrm{CH}$ & 104.7, CH \\
\hline $2^{\prime \prime}$ & 75.7, CH & 75.7, $\mathrm{CH}$ & 75.6, $\mathrm{CH}$ & 75.7, $\mathrm{CH}$ & 75.7, CH & 76.5, CH \\
\hline $3^{\prime \prime}$ & $78.1^{\mathrm{a}}, \mathrm{CH}$ & $78.0^{\mathrm{b}}, \mathrm{CH}$ & $78.0^{\mathrm{c}}, \mathrm{CH}$ & $78.0^{\mathrm{d}}, \mathrm{CH}$ & $78.0^{\mathrm{e}}, \mathrm{CH}$ & $78.0^{\mathrm{f}}, \mathrm{CH}$ \\
\hline $4^{\prime \prime}$ & $70.3, \mathrm{CH}$ & $70.4, \mathrm{CH}$ & $70.4, \mathrm{CH}$ & $70.4, \mathrm{CH}$ & $70.4, \mathrm{CH}$ & 71.4, CH \\
\hline $5^{\prime \prime}$ & $78.2, \mathrm{CH}$ & $78.3, \mathrm{CH}$ & 78.3, CH & $78.3, \mathrm{CH}$ & $78.3, \mathrm{CH}$ & $78.3, \mathrm{CH}$ \\
\hline $6^{\prime \prime}$ & $61.9, \mathrm{CH}_{2}$ & $62.0, \mathrm{CH}_{2}$ & $61.9, \mathrm{CH}_{2}$ & $61.9, \mathrm{CH}_{2}$ & $61.9, \mathrm{CH}_{2}$ & $62.6, \mathrm{CH}_{2}$ \\
\hline $1^{\prime \prime \prime}$ & $104.7, \mathrm{CH}$ & 104.6, CH & $104.7, \mathrm{CH}$ & $104.8, \mathrm{CH}$ & $104.8, \mathrm{CH}$ & 104.6, CH \\
\hline $2^{\prime \prime \prime}$ & $75.3, \mathrm{CH}$ & $75.2, \mathrm{CH}$ & 75.2, $\mathrm{CH}$ & $75.2, \mathrm{CH}$ & $75.2, \mathrm{CH}$ & $75.2, \mathrm{CH}$ \\
\hline $3^{\prime \prime \prime}$ & $78.0^{\mathrm{a}}, \mathrm{CH}$ & $77.9^{\mathrm{b}}, \mathrm{CH}$ & $77.9^{\mathrm{c}}, \mathrm{CH}$ & $78.1^{\mathrm{d}}, \mathrm{CH}$ & $78.1^{\mathrm{e}}, \mathrm{CH}$ & $77.9^{\mathrm{f}}, \mathrm{CH}$ \\
\hline $4^{\prime \prime \prime}$ & 71.4, $\mathrm{CH}$ & 71.4, $\mathrm{CH}$ & $71.3, \mathrm{CH}$ & $71.3, \mathrm{CH}$ & $71.3, \mathrm{CH}$ & 72.0, CH \\
\hline $5^{\prime \prime \prime}$ & $78.4, \mathrm{CH}$ & $78.4, \mathrm{CH}$ & $78.4, \mathrm{CH}$ & $78.4, \mathrm{CH}$ & 78.4, $\mathrm{CH}$ & 78.4, $\mathrm{CH}$ \\
\hline $6^{\prime \prime \prime}$ & 62.6, $\mathrm{CH}_{2}$ & 62.6, $\mathrm{CH}_{2}$ & 62.6, $\mathrm{CH}_{2}$ & 62.6, $\mathrm{CH}_{2}$ & 62.6, $\mathrm{CH}_{2}$ & 63.2, $\mathrm{CH}_{2}$ \\
\hline
\end{tabular}


Table 2 (continued)

\begin{tabular}{|c|c|c|c|c|c|c|}
\hline Position & 1 & 2 & 3 & 4 & 5 & 6 \\
\hline \multicolumn{7}{|c|}{ 21-O-moiety } \\
\hline $1^{\prime \prime \prime \prime}$ & & & 174.0, C & & 179.8, C & 173.9, C \\
\hline $2^{\prime \prime \prime \prime}$ & & & $21.4, \mathrm{CH}_{3}$ & & $35.9, \mathrm{CH}$ & $21.4, \mathrm{CH}_{3}$ \\
\hline $3^{\prime \prime \prime \prime}$ & & & & & $19.5, \mathrm{CH}_{3}$ & \\
\hline $4^{\prime \prime \prime \prime}$ & & & & & $20.2, \mathrm{CH}_{3}$ & \\
\hline \multicolumn{7}{|c|}{ 22- $O$-moiety } \\
\hline $1^{\prime \prime \prime \prime}$ & & $173.5, \mathrm{C}$ & & $179.3, \mathrm{C}$ & & \\
\hline $2^{\prime \prime \prime \prime}$ & & $21.4, \mathrm{CH}_{3}$ & & $35.7, \mathrm{CH}$ & & \\
\hline $3^{\prime \prime \prime \prime}$ & & & & $19.5, \mathrm{CH}_{3}$ & & \\
\hline $4^{\prime \prime \prime \prime}$ & & & & $19.9, \mathrm{CH}_{3}$ & & \\
\hline \multicolumn{7}{|c|}{ 28-O-moiety } \\
\hline $1^{\prime \prime \prime \prime}$ & 173.5, C & $172.8, \mathrm{C}$ & & 172.7, C & & $172.8, \mathrm{C}$ \\
\hline $2^{\prime \prime \prime \prime}$ & $20.9, \mathrm{CH}_{3}$ & $20.9, \mathrm{CH}_{3}$ & & 21.0, $\mathrm{CH}_{3}$ & & $20.9, \mathrm{CH}_{3}$ \\
\hline
\end{tabular}

[Escin Ivg] (7) [17], 21,22-O-diacetylprotoaescigenin 3-O$[\beta$-D-glucopyranosyl $(1 \rightarrow 2)][\beta$-D-glucopyranosyl $(1 \rightarrow 4)]-\beta$ D-glucopyranosiduronic acid [Escin Iv] (8) [18], 22- $O$-angeloylprotoaescigenin $3-O$ - $[\beta$-D-glucopyranosyl $(1 \rightarrow 2)][\beta$ D-glucopyranosyl $(1 \rightarrow 4)]$ - $\beta$-D-glucopyranosiduronic acid [Escin Ivh] (9) [2], 21,28-O-diacetylprotoaescigenin 3-O$[\beta$-D-glucopyranosyl $(1 \rightarrow 2)][\beta$-D-glucopyranosyl $(1 \rightarrow 4)]$ $\beta$-D-glucopyranosiduronic acid [Aesculiside A] (10) [19], 22- $O$-tigloyl-28- $O$-acetylprotoaescigenin $\quad 3-O-[\beta$-D-glucopyranosyl $(1 \rightarrow 2)][\beta$-D-glucopyranosyl $(1 \rightarrow 4)]$ - $\beta$-D-glucopyranosiduronic acid [Escin IVc] (11) [20], 22- $O$ angeloyl-28- $O$-acetylprotoaescigenin $3-O-[\beta$-D-glucopyranosyl $(1 \rightarrow 2)][\beta$-D-glucopyranosyl $(1 \rightarrow 4)]$ - $\beta$-D-glucopyranosiduronic acid [Escin IVd] (12) [20], 21-Otigloylprotoaescigenin 3- $O$ - $[\beta$-D-glucopyranosyl $(1 \rightarrow 2)][\beta$ D-glucopyranosyl $(1 \rightarrow 4)]$ - $\beta$-D-glucopyranosiduronic acid [Aesculioside A] (13) [13], 21-O-angeloylprotoaescigenin 3 - $O$ - $[\beta$-D-glucopyranosyl $(1 \rightarrow 2)][\beta$-D-glucopyra-

$\operatorname{nosyl}(1 \rightarrow 4)$ ]- $\beta$-D-glucopyranosiduronic acid [Aesculioside B] (14) [13], 21- $O$-isobutyryl-22- $O$-acetylprotoaescigenin 3 - $O$ - $[\beta$-D-glucopyranosyl $(1 \rightarrow 2)][\beta$-D-glucopyra-

$\operatorname{nosyl}(1 \rightarrow 4)]-\beta$-D-glucopyranosiduronic acid [Escin V] (15) [18], 21- $O$-tigloyl-22- $O$-acetylprotoaescigenin $3-O$ - $[\beta$-Dglucopyranosyl $(1 \rightarrow 2)][\beta$-D-glucopyranosyl $(1 \rightarrow 4)]-\beta$-Dglucopyranosiduronic acid (Escin Ia) (16) [20], 21- $O$ isobutyryl-28- $O$-acetylprotoaescigenin $3-O-[\beta$-D-glucopy$\operatorname{ranosyl}(1 \rightarrow 2)][\beta$-D-glucopyranosyl $(1 \rightarrow 4)]$ - $\beta$-D-glucopyranosiduronic acid [Isoescin V] (17) [18], 21- $O$-angeloyl-22$O$-acetylprotoaescigenin $3-O$-[ $\beta$-D-glucopyranosyl $(1 \rightarrow 2)$ ] [ $\beta$-D-glucopyranosyl $(1 \rightarrow 4)]$ - $\beta$-D-glucopyranosiduronic acid (Escin Ib) (18) [21], 21-O-isovaleryl-22-O-acetylprotoaescigenin 3 - $O$-[ $\beta$-D-glucopyranosyl $\quad(1 \rightarrow 2)][\beta$-D-glucopyranosyl $(1 \rightarrow 4)$ ]- $\beta$-D-glucopyranosiduronic acid [Esvin VI] (19) [18], 21-O-tigloyl-28- $O$-acetylprotoaescigenin
3- $O$-[ $\beta$-D-glucopyranosyl $\quad(1 \rightarrow 2)] \quad[\beta$-D-glucopyra$\operatorname{nosyl}(1 \rightarrow 4)]-\beta$-D-glucopyranosiduronic acid (isoescin Ia) (20) [20], 21- $O$-angeloyl-28- $O$-acetylprotoaescigenin 3- $O$ $[\beta$-D-glucopyranosyl $(1 \rightarrow 2)][\beta$-D-glucopyranosyl $(1 \rightarrow 4)]$ $\beta$-D-glucopyranosiduronic acid (isoescin Ib) (21) [20], 21-O-tigloyl-22- $O$-acetylprotoaescigenin $3-O-[\beta$-D-galactopyranosyl $(1 \rightarrow 2)] \quad[\beta$-D-glucopyranosyl $(1 \rightarrow 4)]-\beta$-D-glucopyranosiduronic acid (22) [22], 21-O-tigloyl-22-Oacetylbarringtogenol $\quad \mathrm{C} \quad 3-O-[\beta$-D-glucopyranosyl $(1 \rightarrow 2)][\beta$-D-glucopyranosyl $(1 \rightarrow 4)]$ - $\beta$-D-glucopyranosiduronic acid [Escin IIIa] (23) [21], 21-O-tigloyl-28-Oacetylbarringtogenol $\quad \mathrm{C} \quad 3-O-[\beta$-D-glucopyranosyl $(1 \rightarrow 2)][\beta$-D-glucopyranosyl $(1 \rightarrow 4)]-\beta$-D-glucopyra-

nosiduronic acid [Isoescin IIIa] (24) [21], 21-O-angeloyl28 - $O$-acetylbarringtogenol C 3-O-[ $\beta$-D-glucopyranosyl $(1 \rightarrow 2)][\beta$-D-glucopyranosyl $(1 \rightarrow 4)]$ - $\beta$-D-glucopyranosiduronic acid [Isoescin IIIb] (25) [11].

The known compounds 7-9, 12-17, 19, and 22-25 were evaluated for their in vitro cytotoxicities against human cancer cell line (MCF-7) using the MTT method as reported previously [14], with cis-platin as positive control (Table 3). Compound 23 showed significant toxicity effect against MCF-7 with $\mathrm{IC}_{50}$ value of $7.1 \mu \mathrm{M}$, while $\mathbf{1 5}$ and $\mathbf{2 4}$ showed moderate cytotoxicities against MCF-7 cell line, with $\mathrm{IC}_{50}$ values of 16.9 and $11.8 \mu \mathrm{M}$, respectively.

\section{Experimental Section}

\subsection{General Experimental Procedures}

Optical rotations were measured with Perkin Elmer/Model343 digital polarimeter. IR spectra were recorded on a JASCO FT/IR-480 spectrophotometer and reported as 
wave number $\left(\mathrm{cm}^{-1}\right) .{ }^{1} \mathrm{H},{ }^{13} \mathrm{C}$ NMR spectra and 2D NMR spectra were recorded on a Bruker Avance III 600 spectrometer. Chemical shifts were reported using TMS as the internal standard. HR-ESI-MS data were obtained on a Bruker Apex IV FT-MS spectrometer. Column chromatography (CC) was carried out using D-101 macroreticular resin (Tianjin Polymer Technology Co. Ltd.), MCI gel (75-150 $\mu \mathrm{m}$, Mitsubishi Chemical Industries, Japan) and silica gel (90-200 $\mu \mathrm{m}$; Qingdao Marine Chemical Co. Ltd., Qingdao, People's Republic of China). MPLC was performed on a Lisui EZ Purify III System packed with RP-18 silica gel (40-63 $\mu \mathrm{m}$, Merck, 71 Darmstadt, Germany) columns. Precoated silica gel GF254 plates (Qingdao Marine Chemical Co. Ltd, Qingdao, People's Republic of China) were used for thin-layer chromatography (TLC). Preparative HPLC was performed on Shimadzu LC-8A equipped with a Shimadzu PRCODS(K) column and Agilent 1100 apparatus equipped with a Zorbax SB-C-1875 (Agilent, $9.4 \mathrm{~mm} \times 25 \mathrm{~cm}$ ) column, respectively.

\subsection{Plant Material}

The seeds of A. chinensis were collected from Enshi, Hubei Province, P. R. China in October 2014, and were identified by Dr. Wei Sun (Institute of Chinese Materia Medica, China Academy of Chinese Medical Sciences). A voucher specimen $(201410 \mathrm{M})$ was deposited in the herbarium at the department of medicinal plants, Institute of Chinese Materia Medica, China Academy of Chinese Medical Sciences (Beijing 100700, China).

Table 3 Cytotoxicities of compounds 7-9, 12-17, 19, and 22-25 against MCF-7 tumor cell line with $\mathrm{IC}_{50}(\mu \mathrm{M})$

\begin{tabular}{ll}
\hline Compound & $\mathrm{IC}_{50}(\mu \mathrm{M})$ \\
\hline $\mathbf{7}$ & $>40$ \\
$\mathbf{8}$ & $>40$ \\
$\mathbf{9}$ & $>40$ \\
$\mathbf{1 2}$ & $>40$ \\
$\mathbf{1 3}$ & $>40$ \\
$\mathbf{1 4}$ & $>40$ \\
$\mathbf{1 5}$ & 16.9 \\
$\mathbf{1 6}$ & 31.3 \\
$\mathbf{1 7}$ & $>40$ \\
$\mathbf{1 9}$ & 23.9 \\
$\mathbf{2 2}$ & $>40$ \\
$\mathbf{2 3}$ & 7.1 \\
$\mathbf{2 4}$ & 11.8 \\
$\mathbf{2 5}$ & 29.5 \\
Cis-platin $^{\mathrm{a}}$ & 13.0 \\
\hline
\end{tabular}

${ }^{\mathrm{a}}$ Positive control

\subsection{Extraction and Isolation}

The dried seeds of $A$. chinensis $(10 \mathrm{~kg})$ were extracted with $70 \%$ ethanol under reflux for three times $(3,2$, and $1 \mathrm{~h}$, respectively). The resultant extract was resolved in $\mathrm{H}_{2} \mathrm{O}$ and extracted with EtOAc for three times. After removal of the EtOAc fraction, the remaining solution was then extracted with butanol for three times. The butanol solution was concentrated under reduced pressure and the butanol fraction $(56 \mathrm{~g})$ was subjected to D-101 (eluted with $20 \%$ ethanol, $40 \%$ ethanol, $70 \%$ ethanol and $95 \%$ ethanol) to afford four fractions. The $40 \%$ ethanol-eluted fraction $(12 \mathrm{~g})$ was decolorized over MCI gel (eluted with $90 \%$ $\mathrm{MeOH})$ and then was subjected to MPLC $\left(\mathrm{MeOH} / \mathrm{H}_{2} \mathrm{O}\right.$ 5-35\%) to provide Frs. 1-5. Frs. 1 (4.8 g) was further separated by using repeated prep. HPLC $\left(\mathrm{MeOH} / \mathrm{H}_{2} \mathrm{O}\right.$ $8-20 \%)$ to give five subfractions, Frs. 1A-1E. Subfraction Frs. 1A $(0.4 \mathrm{~g})$ was purified by semipreparative HPLC (MeCN/ $\left.\mathrm{H}_{2} \mathrm{O}, 11 \%\right)$ to afford compounds $1(11 \mathrm{mg}), 7$ $(8 \mathrm{mg}), \boldsymbol{8}(23 \mathrm{mg})$, and $\mathbf{9}(4 \mathrm{mg})$. Compounds $\mathbf{2}(5 \mathrm{mg}), \mathbf{3}$ (4 mg), $\mathbf{1 0}(16 \mathrm{mg}), \mathbf{1 1}(5 \mathrm{mg}), \mathbf{1 2}(7 \mathrm{mg})$, and $\mathbf{1 3}(8 \mathrm{mg})$ were obtained by two times of semipreparative HPLC $\left(\mathrm{MeCN} / \mathrm{H}_{2} \mathrm{O}, 13 \%\right)$ from Frs. 1B $(0.6 \mathrm{~g})$. Subfraction Frs. 1C $(0.1 \mathrm{~g})$ was separated by semipreparative HPLC $\left(\mathrm{MeOH} / \mathrm{H}_{2} \mathrm{O}, 15 \%\right)$ to afford $4(2 \mathrm{mg})$ and $5(1 \mathrm{mg})$. Subfraction Frs. 1D (0.3 g) was subjected to semipreparative HPLC $\left(\mathrm{MeOH} / \mathrm{H}_{2} \mathrm{O}, 18 \%\right)$ to give compounds 6 (8 mg), 14 (5 mg), 15 (2 mg), and $22(4 \mathrm{mg})$. Compounds $\mathbf{1 6}(6 \mathrm{mg}), \mathbf{1 7}(11 \mathrm{mg})$, and $\mathbf{1 8}(15 \mathrm{mg})$ were obtained from Frs. 2 by repeated prep. HPLC purification. Frs. 3 was subjected to repeated prep. HPLC and semi-perp. HPLC to afford compounds $19(5 \mathrm{mg})$ and $23(2 \mathrm{mg})$. From Frs. 4 and Frs. 5, compounds 20 (4 mg), 21 (4 mg), 24 (3 mg) and $25(1 \mathrm{mg})$ were obtained by repeated prep. HPLC and semi-perp. HPLC.

\subsubsection{Aesculusoside A (1)}

Amorphous powder; $[\alpha]_{\mathrm{D}}^{25}-2.5(c 0.1, \mathrm{MeOH})$; IR $(\mathrm{KBr})$ 3423, 2951, 1721, 1380, 1261, $1031 \mathrm{~cm}^{-1} ;{ }^{1} \mathrm{H}$ and ${ }^{13} \mathrm{C}$ NMR data: see Tables 1 and 2; HR-ESI-MS $(\mathrm{m} / \mathrm{z}$ $1047.5035\left([\mathrm{M}-\mathrm{H}]^{-}\right)$, calc. 1047.5018).

\subsubsection{Aesculusoside B (2)}

Amorphous powder; $[\alpha]_{\mathrm{D}}^{25}-3.5(c 0.1, \mathrm{MeOH})$; IR $(\mathrm{KBr})$ $3421,2945,1725,1384,1272,1077 \mathrm{~cm}^{-1} ;{ }^{1} \mathrm{H}$ and ${ }^{13} \mathrm{C}$ NMR data: see Tables 1 and 2; HR-ESI-MS $(\mathrm{m} / \mathrm{z}$ $1089.5107\left([\mathrm{M}-\mathrm{H}]^{-}\right)$, calc. 1089.5123). 


\subsubsection{Aesculusoside C (3)}

Amorphous powder; $[\alpha]_{\mathrm{D}}^{25}-34.5(c 0.1, \mathrm{MeOH}) ; \mathrm{IR}(\mathrm{KBr})$ 3422, 2928, 1720, 1383,1273, $1076 \mathrm{~cm}^{-1} ;{ }^{1} \mathrm{H}$ and ${ }^{13} \mathrm{C}$ NMR data: see Tables 1 and 2; HR-ESI-MS $(\mathrm{m} / \mathrm{z}$ $1047.5005\left([\mathrm{M}-\mathrm{H}]^{-}\right)$, calc. 1047.5018).

\subsubsection{Aesculusoside D (4)}

Amorphous powder; $[\alpha]_{\mathrm{D}}^{25}-32.1($ c $0.1, \mathrm{MeOH})$; IR $(\mathrm{KBr})$ $3421,2946,1723,1383,1277,1074 \mathrm{~cm}^{-1} ;{ }^{1} \mathrm{H}$ and ${ }^{13} \mathrm{C}$ NMR data: see Tables 1 and 2; HR-ESI-MS $(\mathrm{m} / \mathrm{z}$ $1117.5425\left([\mathrm{M}-\mathrm{H}]^{-}\right)$, (calc. 1117.5436).

\subsubsection{Aesculusoside E (5)}

Amorphous powder; $[\alpha]_{\mathrm{D}}^{25}-2.5(c 0.1, \mathrm{MeOH})$; ) IR (KBr) $3423,2930,1721,1375,1277,1075 \mathrm{~cm}^{-1} ;{ }^{1} \mathrm{H}$ and ${ }^{13} \mathrm{C}$ NMR data: see Tables 1 and 2; HR-ESI-MS $(\mathrm{m} / \mathrm{z}$ $1075.5406\left([\mathrm{M}-\mathrm{H}]^{-}\right)$, (calc. 1075.5331).

\subsubsection{Aesculusoside F (6)}

Amorphous powder; $[\alpha]_{\mathrm{D}}^{25}-2.8(c$ 0.1, $\mathrm{MeOH})$; IR $(\mathrm{KBr})$ $3423,2929,1721,1384,1273,1075 \mathrm{~cm}^{-1} ;{ }^{1} \mathrm{H}$ and ${ }^{13} \mathrm{C}$ NMR data: see Tables 1 and 2; HR-ESI-MS (1073.5162 $\left([\mathrm{M}-\mathrm{H}]^{-}\right)$, (calc. 1073.5174).

\subsection{Cytotoxicity Assay}

Compounds were tested in vitro for their cytotoxicities against proliferation of MCF-7 (breast cancer) using the MTT method [14]. The human tumor cell line MCF-7 was obtained from ATCC (Manassas, VA, USA). All cells were cultured in DMEM medium (Biological Industries, Kibbutz Beit-Haemek, Israel), which were supplemented with $10 \%$ fetal bovine serum (Biological Industries, Kibbutz BeitHaemek, Israel) at $37{ }^{\circ} \mathrm{C}$ in a humidified atmosphere containing $5 \% \mathrm{CO}_{2}$. Briefly, cells were seeded into each well of a 96-well cell culture plate. After $12 \mathrm{~h}$ of incubation at $37^{\circ} \mathrm{C}$, the test compound $(40 \mu \mathrm{M})$ was added. After incubation for $48 \mathrm{~h}$, cells were subjected to the MTT assay. Compounds with a growth inhibition rate of $50 \%$ were further evaluated with cis-platin (Sigma, St. Louis, MO, USA) as positive control.

\subsection{Acid Hydrolysis of Compounds 1 and 6}

A solution of compound $1(4 \mathrm{mg})$ in $\mathrm{H}_{2} \mathrm{O}(1 \mathrm{~mL})$ was treated with $20 \%$ aqueous $\mathrm{H}_{2} \mathrm{SO}_{4}(1 \mathrm{~mL})$, and the mixture was heated under reflux for $2 \mathrm{~h}$. It was then neutralized by saturated $\mathrm{NaHCO}_{3}$ and extracted three times with EtOAc. Glucose and glucuronic acid were obtained from the $\mathrm{H}_{2} \mathrm{O}$ layer, and identified by comparison with authentic samples and by PC (Paper Chromatography) behavior, solvent: $\mathrm{CHCl}_{3}-\mathrm{MeOH}-\mathrm{H}_{2} \mathrm{O}, 10: 6: 1$.

\subsection{Alkaline Hydrolysis of Compound 1}

Compound 1 (5 mg) was added to a $\mathrm{MeOH}$ solution ( $5 \mathrm{ml}$ ) of $\mathrm{NaOMe}(1 \mathrm{mg})$. The mixture was stirred at room temperature for $4 \mathrm{~h}$ and then neutralized with $20 \%$ aqueous $\mathrm{HCl}$. The reaction mixture was concentrated under reduced pressure, and the residue was purified by column chromatography on silica gel $\left(\mathrm{CH}_{2} \mathrm{Cl}_{2} / \mathrm{MeOH} 2: 1-1: 1\right)$ to furnish aesculuside-B (1.2 mg, $46 \%$ yield), which was identical with authentic sample by TLC, ${ }^{1} \mathrm{H}$ - and ${ }^{13} \mathrm{C}-\mathrm{NMR}$ spectra comparisons [15].

Acknowledgements We gratefully acknowledge financial support from the independent topics supported by operational expenses for basic research of China Academy of Chinese Medical Sciences (ZXKT15032).

\section{Compliance with Ethical Standards}

Conflict of interest The authors declare no conflicts of interest.

Open Access This article is distributed under the terms of the Creative Commons Attribution 4.0 International License (http://creative commons.org/licenses/by/4.0/), which permits unrestricted use, distribution, and reproduction in any medium, provided you give appropriate credit to the original author(s) and the source, provide a link to the Creative Commons license, and indicate if changes were made.

\section{References}

1. Z. Zhang, S. Li, X.Y. Lian, Crops 1, 24-51 (2010)

2. F. Wei, L.Y. Ma, W.T. Jin, S.C. Ma, G.Z. Han, I.A. Khan, R.C. Lin, Chem. Pharm. Bull. 52, 1246-1248 (2004)

3. H. Matsuda, Y. Li, T. Murakami, K. Ninomiya, J. Yamahara, M. Yoshikawa, Biol. Pharm. Bull. 20, 1092-1095 (1997)

4. X.Y. Zhou, F.H. Fu, Z. Li, Q.J. Dong, J. He, C.H. Wang, Planta Med. 75, 1580-1585 (2009)

5. Y.P. Niu, L.D. Li, L.M. Wu, Lymphoma 49, 1384-1391 (2008)

6. Y.P. Niu, L.M. Wu, Y.L. Jiang, W.X. Wang, L.D. Li, J. Pharm. Pharmacol. 60, 1213-1220 (2008)

7. J.M.R. Patlolla, J. Raju, M.V. Swamy, C.V. Rao, Mol. Cancer Ther. 5, 1459-1466 (2006)

8. X.W. Yang, J. Zhao, Y.X. Cui, X.H. Liu, C.M. Ma, M. Hattori, L.H. Zhang, J. Nat. Prod. 62, 1510-1513 (1999)

9. I. Kucukkurt, S. Ince, H. Keles, E.K. Akkol, G. Avci, E. Yesilada, E. Bacak, J. Ethnopharmacol. 129, 18-22 (2010)

10. I. Sato, T. Suzuki, H. Kobayashi, S. Tsuda, J. Vet. Med. Sci. 67, 731-734 (2005)

11. J. Zhao, X.W. Yang, J. Asian Nat. Prod. Res. 5, 197-203 (2003)

12. J. Zhao, X.W. Yang, M. Hattori, Chem. Pharm. Bull. 49, 626-628 (2001)

13. Z. Zhang, K. Koike, Z. Jia, T. Nikaido, D. Guo, J. Zheng, Chem. Pharm. Bull. 47, 1515-1520 (1999) 
14. T. Mosmann, J. Immunol. Methods 65, 55-63 (1983)

15. B. Singh, P.K. Agrawal, R.S. Thakur, J. Nat. Prod. 50, 781-783 (1987)

16. M. Yoshikawa, E. Harada, T. Murakami, H. Matsuda, N. Wariishi, J. Yamahara, N. Murakami, I. Kitagawa, Chem. Pharm. Bull. 42, 1357-1359 (1994)

17. X.W. Yang, J. Zhao, Y.X. Cui, Chin. Chem. Lett. 11, 139-142 (2000)
18. M. Yoshikawa, T. Murakami, J. Yamahara, H. Matsuda, Chem. Pharm. Bull. 46, 1764-1769 (1998)

19. X.W. Yang, J. Guo, Zhongguo Xinyao Zazhi 16, 1373-1376 (2007)

20. J. Guo, X.W. Yang, J. Chin. Pharm. Sci. 13, 87-91 (2004)

21. X. Yang, J. Zhao, S. Ouyang, Zhongcaoyao 33, 389-391 (2002)

22. F. Wei, L. Ma, S. Ma, R. Lin, Yaowu Fenxi Zazhi 24, 400-402 (2004) 